\title{
Simultaneous Optimization of Correlated Multiple Surface Quality Characteristics of Mild Steel Turned Product
}

\author{
Saurav DATTA, Siba Sankar MAHAPATRA \\ Department of Mechanical Engineering, National Institute of Technology, Rourkela, India \\ Email:sdattaju@gmail.com,mahapatrass2003@yahoo.com
}

\begin{abstract}
Present work highlights application of utility theory combined with Principal Component Analysis (PCA) and Taguchi's robust design for simultaneous optimization of correlated multiple surface quality characteristics of mild steel machined product prepared by straight turning operation. The study aims at evaluating the most favorable process environment followed by an optimal parametric combination for achieving high surface quality. Traditional Taguchi based hybrid optimization approaches rely on the assumption that quality indices are uncorrelated or independent. But it is felt that, in practice, there may be some correlation among various quality indices (responses) under consideration. To overcome this limitation of Taguchi approach, the present study proposes application of PCA to convert correlated responses into uncorrelated quality indices called principal components. Finally based on utility theory, Taguchi method has been applied to solve this optimization problem. The study demonstrates detailed methodology and concludes robustness and flexibility of the proposed optimization technique and validates its effectiveness through a case study in which correlated multiple response characteristics of turning operation have been optimized.
\end{abstract}

Keywords: utility theory, principal component analysis, Taguchi's robust design, straight turning

\section{Introduction}

Literature depicts that a considerable amount of work has been carried out by previous investigators for modeling, simulation and parametric optimization of surface properties of the product in turning operation. Apart from optimizing a single response (process output), multiobjective optimization problems have also been solved using Taguchi method followed by grey relation theory.

Lin et al. [1] adopted an abdicative network to construct a prediction model for surface roughness and cutting force. Feng and Wang [2] investigated for the prediction of surface roughness in finish turning operation by developing an empirical model through considering working parameters: work piece hardness (material), feed, cutting tool point angle, depth of cut, spindle speed, and cutting time. Data mining techniques, nonlinear regression analysis with logarithmic data transformation were employed for developing the empirical model to predict the surface roughness.

Suresh et al. [3] focused on machining mild steel by TiN-coated tungsten carbide (CNMG) cutting tools for developing a surface roughness prediction model by using Response Surface Methodology (RSM). Genetic
Algorithms (GA) used to optimize the objective function and compared with RSM results. Kirby et al. [4] developed the prediction model for surface roughness in turning operation. Özel and Karpat [5] studied for prediction of surface roughness and tool flank wear by utilizing the neural network model in comparison with regression model. Kohli and Dixit [6] proposed a neural-networkbased methodology with the acceleration of the radial vibration of the tool holder as feedback. For the surface roughness prediction in turning process the back-propagation algorithm was used for training the network model. Pal and Chakraborty [7] studied on development of a back propagation neural network model for prediction of surface roughness in turning operation and used mild steel work-pieces with high speed steel as the cutting tool for performing a large number of experiments. Ahmed [8] developed the methodology required for obtaining optimal process parameters for prediction of surface roughness in Al turning. Abburi and Dixit [9] developed a knowledge-based system for the prediction of surface roughness in turning process. Fuzzy set theory and neural networks were utilized for this purpose. Zhong et al. [10] predicted the surface roughness of turned surfaces using networks with seven inputs namely 
tool insert grade, work piece material, tool nose radius, rake angle, depth of cut, spindle rate, and feed rate.

Doniavi et al. [11] used response surface methodology (RSM) in order to develop empirical model for the prediction of surface roughness by deciding the optimum cutting condition in turning.

Kassab and Khoshnaw [12] examined the correlation between surface roughness and cutting tool vibration for turning operation. Al-Ahmari [13] developed empirical models for tool life, surface roughness and cutting force for turning operation. The methods used for developing aforesaid models were Response Surface Methodology (RSM) and neural networks (NN).

Thamizhmanii et al. [14] applied Taguchi method for finding out the optimal value of surface roughness under optimum cutting condition in turning SCM 440 alloy steel. Wang and Lan [15] used Orthogonal Array of Taguchi method coupled with grey relational analysis considering four parameters viz. speed, cutting depth, feed rate, tool nose run off etc. for optimizing three responses: surface roughness, tool wear and material removal rate in precision turning on an ECOCA-3807 CNC Lathe. Sahoo et al. [16] studied for optimization of machining parameters combinations emphasizing on fractal characteristics of surface profile generated in CNC turning operation using Taguchi's Orthogonal Array design. Reddy et al. [17] adopted multiple regression model and artificial neural network to deal with surface roughness prediction model for machining of aluminium alloys by CNC turning. Lan et al. [18] considered four cutting parameters: speed, feed, depth of cut, and nose runoff varied in three levels for predicting the surface roughness of CNC turned product. Thamma [19] constructed the regression model to find out the optimal combination of process parameters in turning operation for Aluminium 6061 work pieces. The study highlighted that cutting speed, feed rate, and nose radius had a major impact on surface roughness. Fnides et al. [20] studied on machining of slide-lathing grade X38CrMoV5-1 steel treated at $50 \mathrm{HRC}$ by a mixed ceramic tool (insert CC650) to reveal the influences of cutting parameters: feed rate, cutting speed, depth of cut and flank wear on cutting forces as well as on surface roughness. Biswas et al. [21] studied that on-line flank wear directly influenced the power consumption, quality of the surface finish, tool life, productivity etc. The authors developed a Neuro-Fuzzy model for prediction of the tool wear. Shetty et al. [22] discussed the use of Taguchi and response surface methodologies for minimizing the surface roughness in turning of discontinuously reinforced aluminum composites (DRACs) having aluminum alloy 6061 as the matrix and containing $15 \mathrm{vol}$ \% of silicon carbide particles of mean diameter $25 \mu \mathrm{m}$ under pressured steam jet approach.
Literature highlights immense effort rendered by previous researchers to optimize various response parameters in relation to turning operation. Application of hybrid Taguchi methods has been found widely attempted by the investigators. However, the disadvantage of these approaches is the unrealistic assumption of non-existence of correlation among the responses. To overcome this shortcoming, the present study suggests application of Principal Component Analysis (PCA) to convert correlated responses into uncorrelated quality indices called principal components [23]. Based on quality loss of individual quality indices, an overall utility degree has been computed by exploring the concept of utility theory. Thus, multiple objectives (responses) have been transformed into an equivalent single objective function (overall utility degree) which has been maximized finally by using Taguchi method. To this end the study finally verifies robustness and flexibility of the proposed optimization methodology for solving correlated multi-criteria optimization problem emphasizing off-line quality control in straight turning operation.

\section{Procedure Adapted for Optimization}

The proposed optimization methodology combines Principal Component Analysis (PCA) [23,24], utility concept [25] and Taguchi method [26] based on selected Taguchi's Orthogonal Array (OA) Design of Experiment (DOE). The detailed methodology is described below.

Assuming, the number of experimental runs in Taguchi's OA design is $m$, and the number of quality characteristics is $n$. The experimental results can be expressed by the following series:

$$
\begin{aligned}
& X_{1}, X_{2}, X_{3}, \ldots \ldots \ldots, X_{i}, \ldots ., X_{m} \\
& \text { Here, } \\
& X_{1}=\left\{X_{1}(1), X_{1}(2) \ldots \ldots \ldots X_{1}(k) \ldots . . X_{1}(n)\right\} \\
& X_{i}=\left\{X_{i}(1), X_{i}(2) \ldots \ldots \ldots X_{i}(k) \ldots \ldots X_{i}(n)\right\} \\
& X_{m}=\left\{X_{m}(1), X_{m}(2) \ldots \ldots \ldots X_{m}(k) \ldots . . X_{m}(n)\right\}
\end{aligned}
$$

Here, $X_{i}$ represents the $i$ th experimental results and is called the comparative sequence.

Let, $X_{0}$ be the reference sequence:

Let, $X_{0}=\left\{X_{0}(1), X_{0}(2) \ldots \ldots \ldots X_{0}(k) \ldots . . X_{0}(n)\right\}$

The value of the elements in the reference sequence means the optimal value (ideal or desired value) of the corresponding quality characteristic. $X_{0}$ and $X_{i}$ both includes $n$ elements, and $X_{0}(k)$ and $X_{i}(k)$ represent the numeric value of $k$ th element in the reference sequence and the comparative sequence, respectively, $k=1,2, \ldots \ldots ., n$.

\section{Step 1: Normalization of the responses (quality characteristics)}

When the range of the series is too large or the optimal value of a quality characteristic is too enormous, it will 
cause the influence of some factors to be ignored. The original experimental data must be normalized to eliminate such effect. There are three different types of data normalization according to whether we require the LB (Lower-the-Better), the HB (Higher-the-Better) and NB (Nominal-the-Best). The normalization is taken by the following equations.

1) LB (Lower-the-Better)

$$
X_{i}^{*}(k)=\frac{\min X_{i}(k)}{X_{i}(k)}
$$

2) HB (Higher-the-Better)

$$
X_{i}^{*}(k)=\frac{X_{i}(k)}{\max X_{i}(k)}
$$

3) NB (Nominal-the-Best)

$$
X_{i}^{*}(k)=\frac{\min \left\{X_{i}(k), X_{0 b}(k)\right\}}{\max \left\{X_{i}(k), X_{0 b}(k)\right\}}
$$

Here, $\quad \begin{aligned} & i=1,2, \ldots \ldots . ., m ; \\ & k=1,2, \ldots \ldots \ldots, n\end{aligned}$

$X_{i}^{*}(k)$ is the normalized data of the $k$ th element in the $i$ th sequence.

$X_{0 b}(k)$ is the desired value of the $k$ th quality characteristic. After data normalization, the value of $X_{i}^{*}(k)$ will be between 0 and 1 . The series $X_{i}^{*}, i=$ $1,2,3, \ldots \ldots ., m$. can be viewed as the comparative sequence used in the present case.

Step 2: Checking for correlation between two quality characteristics

$$
\text { Let, } \begin{aligned}
& Q_{i}=\left\{X_{0}^{*}(i), X_{1}^{*}(i), X_{2}^{*}(i), \ldots \ldots \ldots \ldots, X_{m}^{*}(i)\right\} \\
& \text { where } i=1,2, \ldots \ldots ., n .
\end{aligned}
$$

It is the normalized series of the $i$ th quality characteristic. The correlation coefficient between two quality characteristics is calculated by the following equation:

$$
\rho_{j k}=\frac{\operatorname{Cov}\left(Q_{j}, Q_{k}\right)}{\sigma_{Q_{j}} \times \sigma_{Q_{k}}}
$$$$
\Delta_{0, i}(k)=\left\{\begin{array}{l}
\left|X_{0}^{*}(k)-X_{i}^{*}(k)\right|, \text { no significant correlation between quality characteristics } \\
\left|Y_{0}(k)-Y_{i}(k)\right|, \quad \text { Significant correlation between quality characteristics }
\end{array}\right.
$$

$$
\begin{aligned}
j & =1,2,3 \ldots \ldots, n . \\
\text { here, } & k=1,2,3, \ldots \ldots . ., n . \\
j & \neq k
\end{aligned}
$$

Here, $\rho_{j k}$ is the correlation coefficient between quality characteristic $j$ and quality characteristic $k$; $\operatorname{Cov}\left(Q_{j}, Q_{k}\right)$ is the covariance of quality characteristic $j$ and quality characteristic $k ; \sigma_{Q_{j}}$ and $\sigma_{Q_{k}}$ are the standard deviation of quality characteristic $j$ and quality characteristic $k$, respectively.

The correlation is checked by testing the following hypothesis:

$$
\left\{\begin{array}{lr}
H_{0}: \rho_{j k}=0 \quad \text { (There is nocorrelation) } \\
H_{1}: \rho_{j k} \neq 0 \quad \text { (There is correlation) }
\end{array}\right.
$$

\section{Step 3: Calculation of the principal component score}

1) Calculate the Eigenvalue $\lambda_{k}$ and the corresponding eigenvector $\beta_{k}(k=1,2, \ldots \ldots, n)$ from the correlation matrix formed by all quality characteristics.

2) Calculate the principal component scores of the normalized reference sequence and comparative sequences using the equation shown below:

$$
Y_{i}(k)=\sum_{j=1}^{n} X_{i}^{*}(j) \beta_{k j}, \quad i=0,1,2, \ldots \ldots ., m ; k=1,2, \ldots \ldots ., n \text {. }
$$

Here, $Y_{i}(k)$ is the principal component score of the $k$ th element in the ith series. $X_{i}^{*}(j)$ is the normalized value of the $j$ th element in the $i$ th sequence, and $\beta_{k j}$ is the $j$ th element of eigenvector $\beta_{k}$.

\section{Step 4: Estimation of quality loss $\Delta_{0, i}(k)$}

$\Delta_{0, i}(k)$ is the absolute value of difference between $X_{0}(k)$ and $X_{i}(k)$ (difference between desired value and ith experimental value for $k t h$ response. If responses are correlated then instead of using $X_{0}(k)$ and $X_{i}(k), Y_{0}(k)$ and $Y_{i}(k)$ should be used.

\section{Step 5: Adaptation of utility theory: Calculation of overall utility index}

According to the utility theory, if $X_{i}$ is the measure of effectiveness of an attribute (or quality characteristics) $i$ and there are $n$ attributes evaluating the outcome space, then the joint utility function can be expressed as:

$$
U\left(X_{1}, X_{2}, \ldots \ldots \ldots \ldots, X_{n}\right)=f\left(U_{1}\left(X_{1}\right), U_{2}\left(X_{2}\right), \ldots \ldots \ldots \ldots \ldots . . . ., U_{n}\left(X_{n}\right)\right)
$$

Here $U_{i}\left(X_{i}\right)$ is the utility of the $i_{t h}$ attribute.

The overall utility function is the sum of individual utilities if the attributes are independent, and is given as follows: 


$$
U\left(X_{1}, X_{2}, \ldots \ldots \ldots \ldots \ldots, X_{n}\right)=\sum_{i=1}^{n} U_{i}\left(X_{i}\right)
$$

The attributes may be assigned weights depending upon the relative importance or priorities of the characteristics. The overall utility function after assigning weights to the attributes can be expressed as:

$$
U\left(X_{1}, X_{2}, \ldots \ldots \ldots \ldots \ldots, X_{n}\right)=\sum_{i=1}^{n} W_{i} \cdot U_{i}\left(X_{i}\right)
$$

Here $W_{i}$ is the weight assigned to the attribute $i$. The sum of the weights for all the attributes must be equal to 1 .

A preference scale for each quality characteristic is constructed for determining its utility value. Two arbitrary numerical values (preference number) 0 and 9 are assigned to the just acceptable and the best value of the quality characteristic respectively. The preference number $P_{i}$ can be expressed on a logarithmic scale as follows:

$$
P_{i}=A \times \log \left(\frac{X_{i}}{X_{i}^{\prime}}\right)
$$

Here $X_{i}$ is the value of any quality characteristic or attribute $i, X_{i}^{\prime}$ is just acceptable value of quality characteristic or attribute $i$ and $A$ is a constant. The value $A$ can be found by the condition that if $X_{i}=X^{*}$ (where $X^{*}$ is the optimal or best value), then $P_{i}=9$.

Therefore,

$$
\begin{aligned}
A= & \frac{9}{\log \frac{X^{*}}{X_{i}^{\prime}}} \\
& X^{*} \neq X_{i}^{\prime}
\end{aligned}
$$

The overall utility can be expressed as follows:

$$
U=\sum_{i=1}^{n} W_{i} \cdot P_{i}
$$

Subject to the condition: $\sum_{i=1}^{n} W_{i}=1$

Among various quality characteristics types, viz. Lower-the-Better, Higher-the-Better, and Nominal-theBest suggested by Taguchi, the utility function would be Higher-the-Better type. Therefore, if the quality function is maximized, the quality characteristics considered for its evaluation will automatically be optimized (maximized or minimized as the case may be).
In the proposed approach based on quality loss (of principal components) utility values are calculated. Utility values of individual principal components are accumulated to calculate overall utility index. Overall utility index servers as the single objective function for optimization.

\section{Step 6: Optimization of overall utility index using Taguchi method}

Finally overall utility index is optimized (maximized) using Taguchi method. For calculating $\mathrm{S} / \mathrm{N}$ ratio; $\mathrm{HB}$ criterion is selected.

\section{Experiments and Data Collection}

The present study has been done through the following plan of experiment.

1) Checking and preparing the Centre Lathe (Manufactured by - Tussor machine tool India Pvt. Ltd. Coimbatore, India) ready for performing the machining operation.

2) Cutting MS bars (AISI 1040) by power saw and performing initial turning operation in Lathe to get desired dimension of the work pieces.

3) Performing straight turning operation on MS specimen bars with various cutting environments involving various combinations of process control parameters like: spindle speed, feed and depth of cut. HSS MIRANDA S-400 tool has been used.

4) Measuring surface roughness and surface profile with the help of a portable stylus-type profilometer, $\mathrm{Ta}$ lysurf (Taylor Hobson, Surtronic 3+, UK) [Figure 1]

5) Data analysis

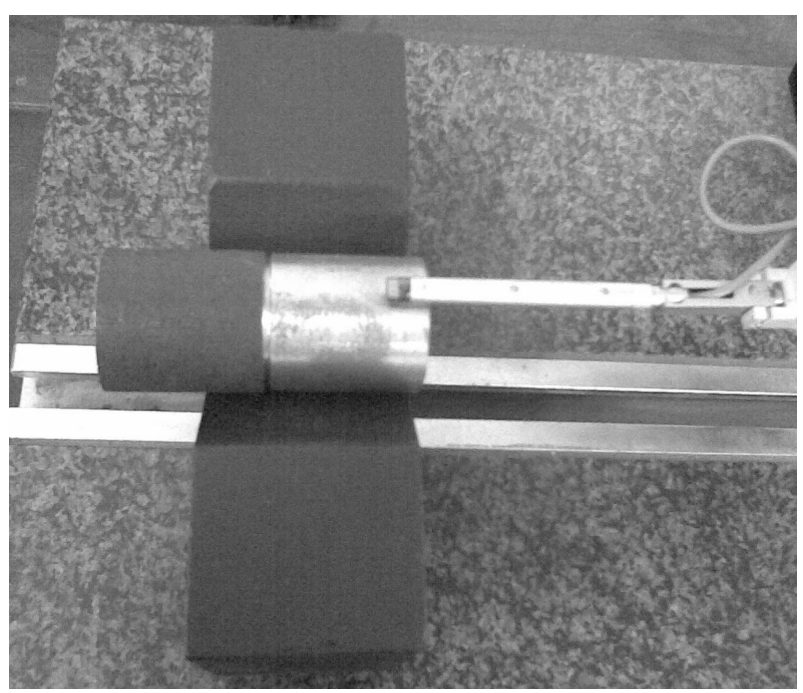

Figure 1. Photographic view of stylus during surface roughness measurement 
Table 1. Process variables and their limits

\begin{tabular}{cccc}
\hline \multicolumn{3}{c}{ Process variables } \\
\hline $\begin{array}{c}\text { Values in } \\
\text { coded form }\end{array}$ & $\begin{array}{c}\text { Spindle Speed } \\
(N) \\
(\mathrm{RPM})\end{array}$ & $\begin{array}{c}\text { Feed } \\
(f) \\
(\mathrm{mm} / \mathrm{rev})\end{array}$ & $\begin{array}{c}\text { Depth of cut } \\
(d) \\
(\mathrm{mm})\end{array}$ \\
\hline-1 & 220 & 0.044 & 0.4 \\
0 & 530 & 0.088 & 0.8 \\
+1 & 860 & 0.132 & 1.2 \\
\hline
\end{tabular}

Table 2. Taguchi's $L_{9}$ orthogonal array

\begin{tabular}{cccc}
\hline & \multicolumn{3}{c}{ Factorial combination } \\
\cline { 2 - 4 } S1. No. & $A$ & $B$ & $C$ \\
\hline 1 & -1 & -1 & -1 \\
2 & -1 & 0 & 0 \\
3 & -1 & 1 & 1 \\
4 & 0 & -1 & 0 \\
5 & 0 & 0 & 1 \\
6 & 0 & 1 & -1 \\
7 & 1 & -1 & 1 \\
8 & 1 & 0 & -1 \\
9 & 1 & 1 & 0 \\
\hline
\end{tabular}

\subsection{Process Variables and Their Limits}

The working ranges of the parameters for subsequent design of experiment, based on Taguchi's $\mathrm{L}_{9}$ Orthogonal Array (OA) design have been selected. In the present experimental study, spindle speed, feed rate and depth of cut have been considered as process variables. The process variables with their units (and notations) are listed in Table 1.

\subsection{Design of Experiment}

Experiments have been carried out using Taguchi's $\mathrm{L}_{9}$ Orthogonal Array (OA) experimental design which consists of 9 combinations of spindle speed, longitudinal feed rate and depth of cut. According to the design catalogue [Peace, G., S., (1993)] prepared by Taguchi, L 9 Orthogonal Array design of experiment has been found suitable in the present work. It considers three process parameters (without interaction) to be varied in three discrete levels. The experimental design has been shown in Table 2 (all factors are in coded form).

The coded number for variables used in Tables 1 and 2 are obtained from the following transformation equations:

$$
\text { Spindle speed: } A=\frac{N-N_{0}}{\Delta N}
$$

Table 3. Various surface roughness parameters and their formulae

\begin{tabular}{|c|c|c|}
\hline Parameter & Description & Formula \\
\hline$R_{a}$ & Arithmetic average of absolute values & $R_{a}=\frac{1}{n} \sum_{i=1}^{n}\left|y_{i}\right|$ \\
\hline$R_{q}, R_{R M S}$ & Root mean squared & $R_{q}=\sqrt{\frac{1}{n}} \sum^{n} y_{i}^{2}$ \\
\hline$R_{v}$ & Maximum valley depth & $R_{v}=\min _{i} y_{i}$ \\
\hline$R_{p}$ & Maximum peak height & $R_{p}=\max _{i} y_{i}$ \\
\hline$R_{t}$ & Maximum Height of the Profile & $R_{t}=R_{p}-R_{v}$ \\
\hline$R_{s k}$ & Skew ness & $R_{s k}=\frac{1}{n R_{q}^{3}} \sum_{i=1}^{n} y_{i}^{3}$ \\
\hline$R_{k u}$ & Kurtosis & $R_{k u}=\frac{1}{n R_{q}^{4}} \sum_{i=1}^{n} y_{i}^{4}$ \\
\hline$R_{z D I N}, R_{m}$ & $\begin{array}{l}\text { average distance between the highest peak and } \\
\text { lowest valley in each sampling length, ASME } \\
\text { Y14.36M - } 1996 \text { Surface Texture Symbols }\end{array}$ & $\begin{aligned} R_{z D I N}= & \frac{1}{s} \sum_{i=1} R_{t i}, \text { where } s \text { is the number of sampling lengths, } \\
& \text { and } R_{t i} \text { is } R_{t} \text { for the } i_{t h} \text { sampling length. }\end{aligned}$ \\
\hline$R_{z J I S}$ & $\begin{array}{l}\text { Japanese Industrial Standard for } R_{z} \text {, based on the } \\
\text { five highest peaks and lowest valleys over the } \\
\text { entire sampling length. }\end{array}$ & $\begin{aligned} i_{t h} R_{z J I S}= & \frac{1}{5} \sum_{i=1}^{J} R_{p i}-R_{v i}, \text { where } R_{p i} \text { and } R_{v i} \text { are the } i_{t h} \\
& \text { highest peak, and lowest valley respectively. }\end{aligned}$ \\
\hline
\end{tabular}


Table 4. Experimental data related to surface roughness characteristics

\begin{tabular}{|c|c|c|c|c|c|c|c|c|c|c|c|c|}
\hline \multirow{2}{*}{ S1. No. } & \multicolumn{3}{|c|}{$R_{a}$} & \multicolumn{3}{|c|}{$R_{q}$} & \multicolumn{3}{|c|}{$R_{k u}$} & \multicolumn{3}{|c|}{$R_{s m}$} \\
\hline & Run 1 & Run 2 & Run 3 & Run 1 & Run 2 & Run 3 & Run 1 & Run 2 & Run 3 & Run 1 & Run 2 & Run 3 \\
\hline 1 & 3.12 & 3.29 & 3.05 & 3.96 & 4.09 & 3.73 & 3.60 & 3.53 & 4.98 & 0.115 & 0.114 & 0.104 \\
\hline 2 & 4.05 & 4.76 & 5.35 & 5.11 & 6.05 & 6.56 & 3.71 & 3.97 & 2.72 & 0.130 & 0.164 & 0.190 \\
\hline 3 & 3.84 & 4.04 & 3.83 & 4.71 & 4.93 & 4.69 & 2.76 & 2.98 & 3.09 & 0.124 & 0.122 & 0.131 \\
\hline 4 & 6.56 & 5.61 & 5.10 & 7.90 & 6.67 & 6.23 & 3.01 & 3.13 & 2.76 & 0.201 & 0.183 & 0.160 \\
\hline 5 & 3.75 & 4.24 & 3.11 & 4.62 & 5.22 & 3.89 & 3.16 & 4.30 & 4.09 & 0.138 & 0.138 & 0.138 \\
\hline 6 & 3.23 & 4.15 & 4.24 & 3.97 & 4.93 & 5.25 & 2.90 & 2.68 & 2.67 & 0.145 & 0.151 & 0.156 \\
\hline 7 & 1.30 & 1.46 & 1.43 & 1.54 & 1.85 & 1.77 & 2.76 & 5.36 & 3.51 & 0.0784 & 0.101 & 0.0898 \\
\hline 8 & 4.05 & 3.89 & 3.29 & 4.85 & 4.54 & 3.95 & 2.51 & 2.05 & 2.36 & 0.129 & 0.145 & 0.136 \\
\hline 9 & 3.67 & 4.10 & 3.88 & 4.66 & 4.87 & 4.75 & 3.92 & 2.69 & 3.58 & 0.110 & 0.176 & 0.116 \\
\hline
\end{tabular}

Table 5. Surface roughness characteristics (average values)

\begin{tabular}{ccccc}
\hline S1. No. & $R_{a}(\mu \mathrm{m})$ & $R_{q}(\mu \mathrm{m})$ & $R_{k u}$ & $R_{s m}(\mathrm{~mm})$ \\
\hline 1 & 3.153 & 3.927 & 4.037 & 0.111 \\
2 & 4.720 & 5.907 & 3.467 & 0.161 \\
3 & 3.903 & 4.777 & 2.943 & 0.126 \\
4 & 5.757 & 6.933 & 2.967 & 0.181 \\
5 & 3.700 & 4.577 & 3.850 & 0.138 \\
6 & 3.873 & 4.717 & 2.750 & 0.151 \\
7 & 1.397 & 1.720 & 3.877 & 0.090 \\
8 & 3.743 & 4.447 & 2.307 & 0.137 \\
9 & 3.883 & 4.760 & 3.397 & 0.134 \\
\hline
\end{tabular}

Feed rate: $B=\frac{f-f_{0}}{\Delta f}$

Depth of cut: $C=\frac{d-d_{0}}{\Delta d}$

Here $\mathrm{A}, \mathrm{B}$ and $\mathrm{C}$ are the coded values of the variables $N, f$ and $d$ respectively; $N_{0}, f_{0}$ and $d_{0}$ are the values of spindle speed, feed rate and depth of cut at zero level; $\Delta N, \Delta f$ and $\Delta d$ are the units or intervals of variation in $N, f$ and $d$ respectively.

\subsection{Roughness Parameters under Consideration}

Each of the roughness parameters is calculated using a formula for describing the surface. There are many different roughness parameters in use, but $R_{a}$ is the most common. Other common parameters include $R_{k u}, R_{s m}$, $R_{z}, R_{q}$ and $R_{s k}$. Some parameters are used only in certain industries or within certain countries. Since these parameters reduce all of the information in a profile to a single number, immense care must be taken in applying and interpreting them. Small changes in how the raw profile data is filtered, how the mean line is calculated, and the physics of the measurement can greatly affect the calculated parameter.
Each of the formulas listed in the Table 3 assumes that the roughness profile has been filtered from the raw profile data and the mean line has been calculated. The roughness profile contains $n$ ordered, equally spaced points along the trace, and $y_{i}$ is the vertical distance from the mean line to the $i_{\text {th }}$ data point. Height is assumed to be positive in the up direction, away from the bulk material.

In the present investigation $R_{a}, R_{q}, R_{k u}$ and $R_{s m}$ have been selected for study.

\subsection{Data Collection}

AISI 1040 MS bars (of diameter 32mm and length 40mm) required for conducting the experiment have been prepared first. Nine numbers of samples of same material and same dimensions have been made. Using different levels of the process parameters nine specimens have been turned in lathe accordingly. After machining, surface roughness and surface profile of the turned surface of the jobs have been measured precisely with the help of a portable stylus-type profilometer, Talysurf (Taylor Hobson, Surtronic 3+, UK).

The results of the experiments have been shown in Table 4 in Appendix. Analysis has been made based on data listed in Table 5 in Subsection 3.4. Optimization of vari- 
ous surface roughness characteristics (viz. centre line average $\left(R_{a}\right)$, root mean square roughness $\left(R_{q}\right)$, kurtosis $\left(R_{k u}\right)$ and mean line peak spacing $\left(R_{s m}\right)$ etc.) have been made by Taguchi method coupled with PCA analysis as well as utility concept. Confirmatory tests have also been conducted finally to validate optimal results.

\subsection{Optimization of Correlated Multiple Surface Roughness Characteristics}

Data (Table 5) related to various surface roughness characteristics have been normalized first. For all surface roughness parameters LB criterion (Equation 1) has been selected. It is obvious because reduction in roughness improves smoothness of the machined surface; i.e. it proves surface finish. Normalized experimental data are shown in Table 6.

The Pearson's correlation coefficients between individual responses have been computed using Equation 5. Table 7 represents Pearson's correlation coefficients. It has been observed that all the responses are correlated (coefficient of correlation having non-zero value). Table
8 presents eigenvalues, eigenvectors, accountability proportion (AP) and cumulative accountability proportion (CAP) computed for the four major quality indicators $(\psi)$. It has been found that first three principal components; $\psi_{1}, \psi_{2}, \psi_{3}$ can take care of $73.3 \%, 24.9 \%$ and $1.8 \%$ variability in data respectively. The contribution of forth principal component: $\psi_{4}$ have been found negligible to interpret variability into data $(0 \%)$. Moreover, cumulative accountability proportion (CAP) for first three principal components has been found 100\%. Therefore, forth principal component should be ignored and the first three principal components can be treated as independent or uncorrelated quality indices instead of four correlated surface quality indices. Correlated responses have been transformed into three independent quality indices (major principal components) using Equation 7. These have been furnished in Table 9. Quality loss estimates (difference between ideal and actual gain) for aforesaid major principal components have been calculated (Equation 8) and presented in Table 10. Based on quality loss, utility values corresponding to the four principal components have been computed using Equations 12 and 13.

Table 6. Normalized response data

\begin{tabular}{ccccc}
\hline S1. No. & $R_{a}$ & $R_{q}$ & $R_{k u}$ & $R_{S m}$ \\
\hline Ideal sequence & 1.0000 & 1.0000 & 1.0000 & 1.0000 \\
1 & 0.4431 & 0.4380 & 0.5715 & 0.8108 \\
2 & 0.2960 & 0.2912 & 0.6654 & 0.5590 \\
3 & 0.3579 & 0.3601 & 0.7839 & 0.7143 \\
4 & 0.2427 & 0.2481 & 0.7776 & 0.4972 \\
5 & 0.3776 & 0.3758 & 0.5992 & 0.6522 \\
6 & 0.3607 & 0.3646 & 0.8389 & 0.5960 \\
7 & 1.0000 & 1.0000 & 0.5950 & 1.0000 \\
8 & 0.3732 & 0.3868 & 1.0000 & 0.6569 \\
9 & 0.3598 & 0.3613 & 0.6791 & 0.6716 \\
\hline
\end{tabular}

Table 7. Correlation among quality characteristics

\begin{tabular}{cccc}
\hline Sl. No. & Correlation between responses & Pearson correlation coefficient & Comment \\
\hline 1 & $R_{a}$ and $R_{q}$ & 1.000 & Both are correlated \\
2 & $R_{a}$ and $R_{k u}$ & 0.120 & Both are correlated \\
3 & $R_{a}$ and $R_{s m}$ & 0.940 & Both are correlated \\
5 & $R_{q}$ and $R_{k u}$ & 0.134 & Both are correlated \\
6 & $R_{q}$ and $R_{s m}$ & 0.938 & Both are correlated \\
7 & $R_{k u}$ and $R_{s m}$ & 0.019 & Both are correlated \\
\hline
\end{tabular}


Table 8. Eigenvalues, eigenvectors, accountability proportion (AP) and cumulative accountability proportion (CAP) computed for the four major quality indicators

\begin{tabular}{ccccc}
\hline & $\psi_{1}$ & $\psi_{2}$ & $\psi_{3}$ & $\psi_{4}$ \\
\cline { 2 - 5 } Eigenvalue & 2.9313 & 0.0053 & 0.0733 & 0.0001 \\
\hline \multirow{3}{*}{ Eigenvector } & -0.581 & $\mid-0.017$ & $\mid-0.402$ & $\mid+0.708$ \\
& -0.581 & -0.002 & -0.405 & -0.706 \\
AP & -0.082 & +0.992 & +0.094 & +0.010 \\
CAP & $-0.565 \mid$ & $-0.124 \mid$ & +0.816 & $-0.003 \mid$ \\
\hline
\end{tabular}

Table 9. Major principal components

\begin{tabular}{cccc}
\hline \multirow{2}{*}{ Sl. No. } & \multicolumn{3}{c}{ Major Principal Components } \\
\cline { 2 - 4 } & $\psi_{1}$ & $\psi_{2}$ & $\psi_{3}$ \\
\hline Ideal sequence & -1.8090 & 0.8490 & 0.1030 \\
1 & -1.0169 & 0.4580 & 0.3598 \\
2 & -0.7116 & 0.5851 & 0.2818 \\
3 & -0.8850 & 0.6823 & 0.3668 \\
4 & -0.6298 & 0.7051 & 0.2808 \\
5 & -0.8554 & 0.5064 & 0.2845 \\
6 & -0.8269 & 0.7514 & 0.2725 \\
7 & -1.7758 & 0.4472 & 0.0649 \\
8 & -0.8947 & 0.9034 & 0.3234 \\
9 & -0.8541 & 0.5835 & 0.3209 \\
\hline
\end{tabular}

Table 10. Quality loss estimates (for principal components)

\begin{tabular}{cccc}
\hline \multirow{2}{*}{ Sl. No. } & \multicolumn{3}{c}{ Quality loss estimated corresponding to individual principal components } \\
\cline { 2 - 4 } & $\boldsymbol{\psi}_{1}$ & $\boldsymbol{\psi}_{2}$ & $\boldsymbol{\psi}_{3}$ \\
\hline 1 & 0.7921 & 0.3910 & 0.2568 \\
2 & 1.0974 & 0.2639 & 0.1788 \\
3 & 0.9240 & 0.1667 & 0.2638 \\
4 & 1.1792 & 0.1439 & 0.1778 \\
5 & 0.9536 & 0.3426 & 0.1815 \\
6 & 0.9821 & 0.0976 & 0.1695 \\
7 & 0.0332 & 0.4018 & 0.0381 \\
8 & 0.9143 & 0.0544 & 0.2204 \\
9 & 0.9549 & 0.2655 & 0.2179 \\
\hline
\end{tabular}

Table 11. Utility values related to individual principal components

\begin{tabular}{cccc}
\hline \multirow{2}{*}{ S1. No. } & \multicolumn{3}{c}{ Utility values of individual principal components } \\
\cline { 2 - 4 } & $\boldsymbol{\psi}_{1}$ & $\boldsymbol{\psi}_{2}$ & $\boldsymbol{\psi}_{3}$ \\
\hline 1 & 1.0031 & 0.1224 & 0.1248 \\
2 & 0.1811 & 1.8929 & 1.8099 \\
3 & 0.6149 & 3.9584 & 0.0000 \\
4 & 0.0001 & 4.6218 & 1.8360 \\
5 & 0.5352 & 0.7169 & 1.7386 \\
6 & 0.4612 & 6.3702 & 2.0566 \\
7 & 8.9992 & 0.0004 & 9.0037 \\
8 & 0.6414 & 8.9978 & 0.8371 \\
9 & 0.5319 & 1.8658 & 0.8892 \\
\hline
\end{tabular}


Table 12. Overall utility index

\begin{tabular}{ccc}
\hline Sl. No. & Overall utility index & Corresponding S/N ratio \\
\hline 1 & 0.4167 & -7.6035 \\
2 & 1.2945 & 2.2420 \\
3 & 1.5240 & 3.6597 \\
4 & 2.1524 & 6.6585 \\
5 & 0.9968 & -0.0278 \\
6 & 2.9624 & 9.4329 \\
7 & 6.0005 & 15.5637 \\
8 & 3.4918 & 10.8610 \\
9 & 1.0955 & 0.7922 \\
\hline
\end{tabular}

Table 13. Results of confirmatory experiment

\begin{tabular}{lcc}
\hline & \multicolumn{2}{c}{ Optimal setting } \\
\cline { 2 - 3 } & Prediction & Experiment \\
\hline Level of factors & $A_{1} B_{-1} C_{1}$ & $A_{1} B_{-1} C_{1}$ \\
S/N ratio of Overall utility index & 11.1040 & 16.9610 \\
Overall utility index & 3.5909 & 7.0477 \\
\hline
\end{tabular}

S/N Ratio of overall utility index

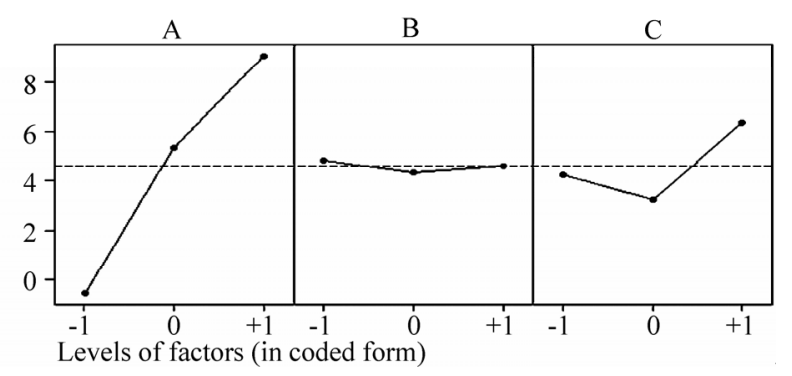

Figure 2. S/N ratio plot for overall utility index

In all the cases minimum observed value of the quality loss (from Table 10) has been considered as its optimal value or most expected value; whereas maximum observed value for the quality loss has been treated as the just acceptable value. Individual utility measures corresponding to three major principal components have been furnished in Table 11. The overall utility index has been computed using Equation 14; tabulated in Table 12 with their corresponding (Signal-to-Noise) $\mathrm{S} / \mathrm{N}$ ratio. In this computation it has been assumed that all quality indices are equally important (same priority weightage, 33.33\%). Figure 2 reflects $\mathrm{S} / \mathrm{N}$ ratio plot for overall utility index; $\mathrm{S} / \mathrm{N}$ ratio being computed using Equation (19).

$$
S N(\text { Higher }- \text { the }- \text { better })=-10 \log \left[\frac{1}{t} \sum_{i=1}^{t} \frac{1}{y_{i}^{2}}\right]
$$

Here $t$ is the number of measurements, and $y_{i}$ the measured ith characteristic value i.e. ith quality indicator. Optimal parameter setting has been evaluated from Figure 2. The optimal setting should confirm highest utility index (HB criterion).

The predicted optimal setting becomes $A_{1} B_{-1} C_{1}$. After evaluating the optimal parameter settings, the next step is to predict and verify the optimal result using the confirmatory test. Table 13 reflects the satisfactory result of confirmatory experiment.

\section{Conclusions}

The foregoing study deals with optimization of multiple surface roughness parameters in search of an optimal parametric combination (favorable process environment) capable of producing desired surface quality of the MS 
turned product. The study proposes an integrated optimization approach using Principal Component Analysis (PCA), utility concept in combination with Taguchi's robust design methodology. The following conclusions may be drawn from the results of the experiments and analysis of the experimental data in connection with correlated multi-response optimization in turning.

1) Application of PCA has been recommended to eliminate response correlation by converting correlated responses into uncorrelated quality indices called principal components which have been as treated as response variables for optimization.

2) Based on accountability proportion (AP) and cumulative accountability proportion (CAP), PCA analysis can reduce the number of response variables to be taken under consideration for optimization. This is really helpful in situations were large number of responses have to be optimized simultaneously.

3) Utility based Taguchi method has been found fruitful for evaluating the optimum parameter setting and solving such a multi-objective optimization problem.

4) The said approach can be recommended for continuous quality improvement and off-line quality control of a process/product.

In the foregoing study, interaction effects of process control parameters have been neglected. But in practical case, this assumption may not be valid. Therefore, there exists scope to incorporate these interactions in the analyses of optimization. If interactive effects of factors are considered, it would be vary interesting to find how Taguchi design of experiment changes from the previous case.

Another disadvantage of this approach is the unrealistic assumption that the responses are treated as equally important (equal priority weight). But, no specific guideline is available on assignment of priority weights to individual responses reflecting their relative importance. These points can be addressed in future.

\section{References}

[1] W. S. Lin, B. Y. Lee, and C. L. Wu, "Modeling the surface roughness and cutting force for turning," Journal of Materials Processing Technology, Vol. 108, pp. 286-293, 2001.

[2] C. X. Feng (Jack) and X. Wang, "Development of empirical models for surface roughness prediction in finish turning," International Journal of Advanced Manufacturing Technology, Vol. 20, pp. 348-356, 2002.

[3] P. V. S. Suresh, P. V. Rao and S. G. Deshmukh, "A genetic algorithmic approach for optimization of surface roughness prediction model," International Journal of Machine Tools and Manufacture, Vol. 42, pp. 675-680, 2002.

[4] E. D. Kirby, Z. Zhang and J. C. Chen, "Development of an accelerometer based surface roughness prediction system in turning operation using multiple regression tech- niques", Journal of Industrial Technology, Vol. 20, No. 4, pp. 1-8, 2004.

[5] T. Özel and Y. Karpat, "Predictive modeling of surface roughness and tool wear in hard turning using regression and neural networks," International Journal of Machine Tools and Manufacture, Vol. 45, pp. 467-479, 2005.

[6] A. Kohli and U. S. Dixit, "A neural-network-based methodology for the prediction of surface roughness in a turning process," International Journal of Advanced Manufacturing Technology, Vol. 25, pp. 118-129, 2005.

[7] S. K. Pal and D. Chakraborty, "Surface roughness prediction in turning using artificial neural network," Neural Computing and Application, Vol. 14, pp. 319-324, 2005.

[8] S. G. Ahmed, "Development of a prediction model for surface roughness in finish turning of aluminium," Sudan Engineering Society Journal, Vol. 52, No. 45, pp. 1-5. 2006

[9] N. R. Abburi and U. S. Dixit, "A knowledge-based system for the prediction of surface roughness in turning process" Robotics and Computer-Integrated Manufacturing, Vol. 22, pp. 363-372, 2006.

[10] Z. W. Zhong, L. P. Khoo and S. T. Han, "Prediction of surface roughness of turned surfaces using neural networks," International Journal of Advance Manufacturing Technology, Vol. 28, pp. 688-693, 2006.

[11] A. Doniavi, M. Eskanderzade and M. Tahmsebian "Empirical modeling of surface roughness in turning process of 1060 steel using factorial design methodology," Journal of Applied Sciences, Vol. 7, No. 17, pp. 2509-2513. 2007.

[12] S. Y. Kassab and Y. K. Khoshnaw, "The effect of cutting tool vibration on surface roughness of work piece in dry turning operation," Engineering and Technology, Vol. 25, No. 7, pp. 879-889, 2007.

[13] A. M. A. Al-Ahmari,"Predictive machinability models for a selected hard material in turning operations," Journal of Materials Processing Technology, Vol. 190, pp. 305-311, 2007.

[14] S. Thamizhmanii, S. Saparudin and S. Hasan, "Analysis of surface roughness by using Taguchi method," Achievements in Materials and Manufacturing Engineering, Vol. 20, No. 1-2, pp. 503-505, 2007.

[15] M. Y. Wang and T. S. Lan, "Parametric optimization on multi-objective precision turning using grey relational analysis," Information Technology Journal, Vol. 7, pp. 1072-1076, 2008.

[16] P. Sahoo, T. K. Barman and B. C. Routara, "Taguchi based practical dimension modeling and optimization in CNC turning," Advance in Production Engineering and Management, Vol. 3, No. 4, pp. 205-217, 2008.

[17] B. S. Reddy, G. Padmanabhan and K. V. K. Reddy, "Surface roughness prediction techniques for CNC turning," Asian Journal of Scientific Research, Vol. 1, No. 3, pp. 256-264, 2008.

[18] T. S. Lan, C. Y. Lo, M. Y. Wang and A. Y. Yen, "Multi quality prediction model of enc turning using back propagation network," Information Technology Journal, Vol. 7, No. 6, pp. 911-917, 2008. 
[19] R. Thamma, "Comparison between multiple regression models to study effect of turning parameters on the surface roughness," Proceedings of the 2008 IAJC-IJME International Conference, ISBN 978-1-606 43-379-9, Paper 133, ENG 103, pp. 1-12, 2008.

[20] B. Fnides, H. Aouici, M. A. Yallese, "Cutting forces and surface roughness in hard turning of hot work steel X38CrMoV5-1 using mixed ceramic," Mechanika, Vol. 2, No. 70, pp. 73-78, 2008.

[21] C. K. Biswas, B. S. Chawla, N. S. Das, E. R. K. N. K. Srinivas, "Tool wear prediction using neuro-fuzzy system", Institution of Engineers (India) Journal (PR), Vol. 89, pp. 42-46, 2008.

[22] R. Shetty, R. Pai, V. Kamath and S. S. Rao, "Study on surface roughness minimization in turning of DRACs using surface roughness methodology and Taguchi under pressured steam jet approach," ARPN Journal of Engineering and Applied Sciences, Vol. 3, No. 1, pp. 59-67, 2008.

[23] S. Datta, G. Nandi, A. Bandyopadhyay and P. K. Pal, "Application of PCA based hybrid Taguchi method for multi-criteria optimization of submerged arc weld: A case study," For International Journal of Advanced Manufacturing Technology, (Article in press) DOI: 10.1007/ s00170-009-1976-0, 2009.

[24] J. Antony, "Multi-response optimization in industrial experiments using Taguchi's quality loss function and Principal Component Analysis," Quality and Reliability Engineering International, Vol. 16, pp. 3-8, 2000.

[25] R. S. Walia, H. S. Shan, and P. Kumar, "Multi-response optimization of CFAAFM process through Taguchi method and utility concept," Materials and Manufacturing Processes, Vol. 21, pp. 907-914, 2006.

[26] S. Datta, A. Bandyopadhyay, and P. K. Pal, “Application of Taguchi philosophy for parametric optimization of bead geometry and HAZ width in submerged arc welding using mixture of fresh flux and fused slag", for International Journal of Advanced Manufacturing Technology, Vol. 36, pp. 689-698, 2008. 
APPENDIX

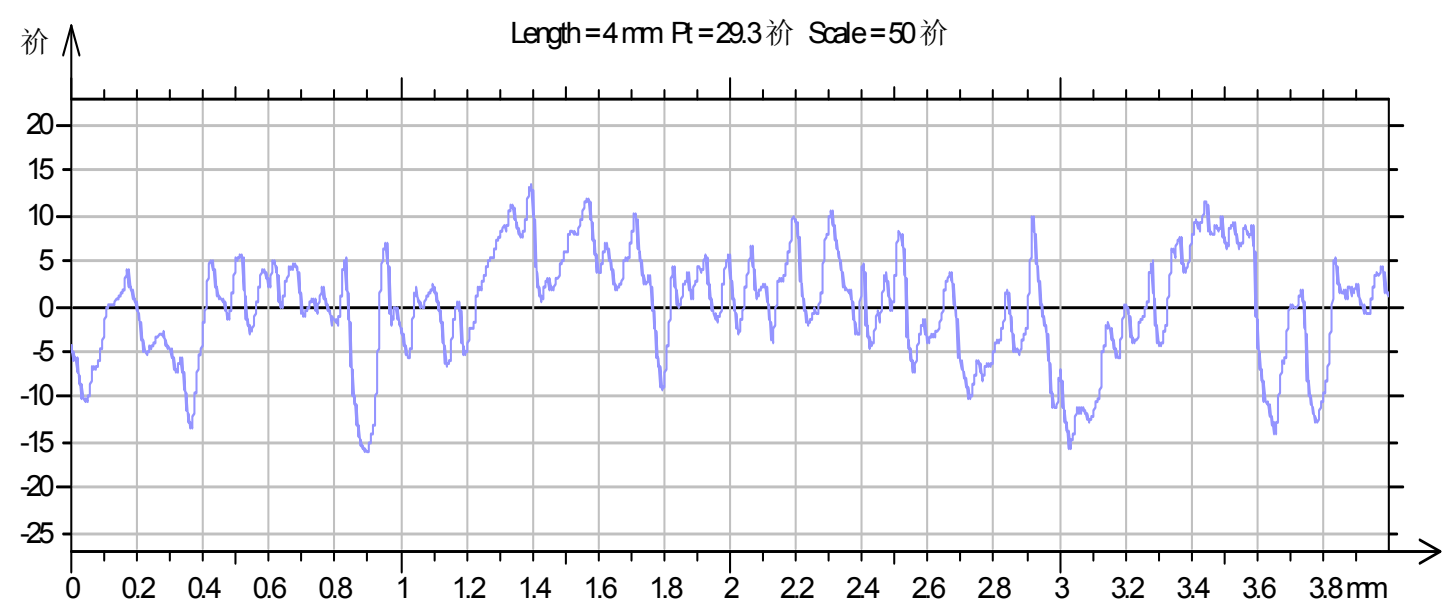

(Sample 1: Run 1) Surface roughness and waviness profile curve at factor setting

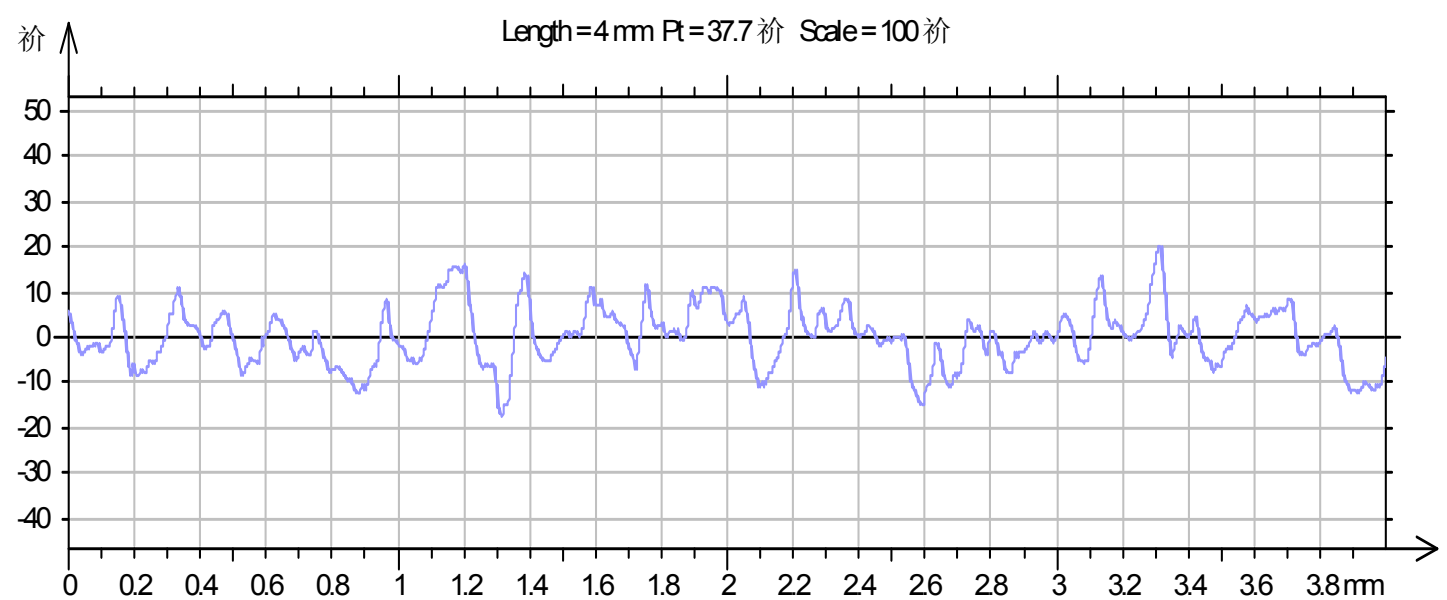

(Sample 2: Run 1) Surface roughness and waviness profile curve at factor setting

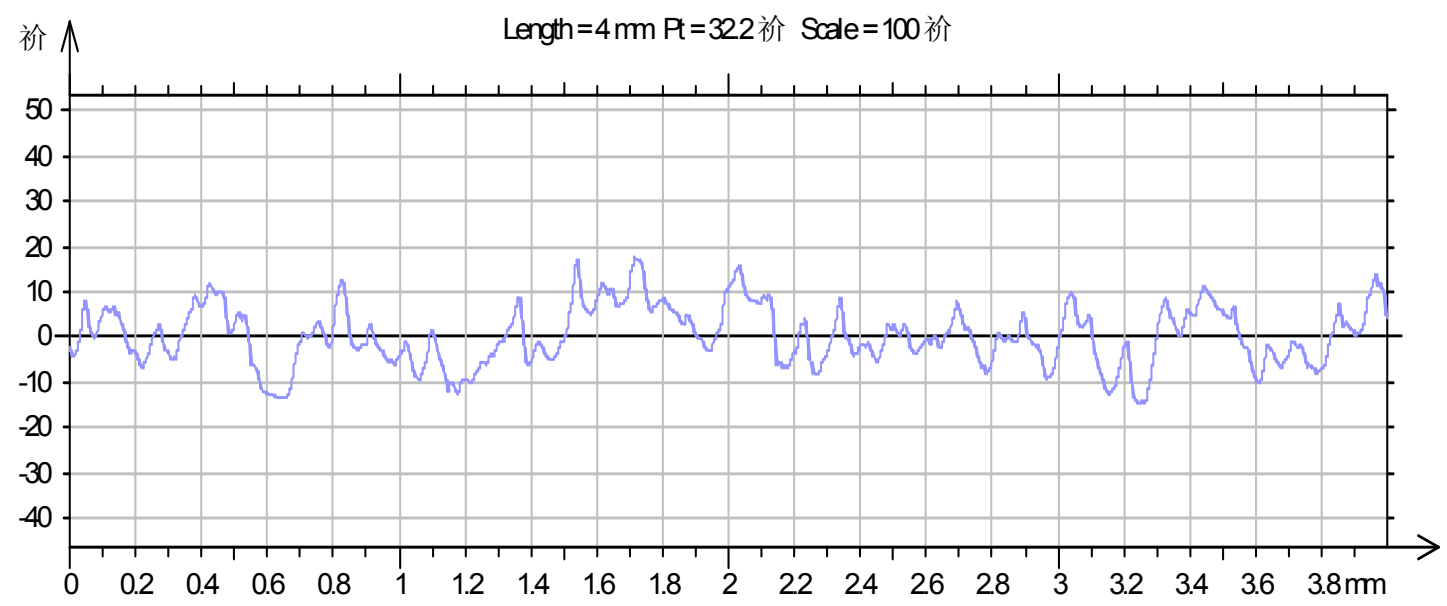

(Sample 3: Run 1) Surface roughness and waviness profile curve at factor setting 


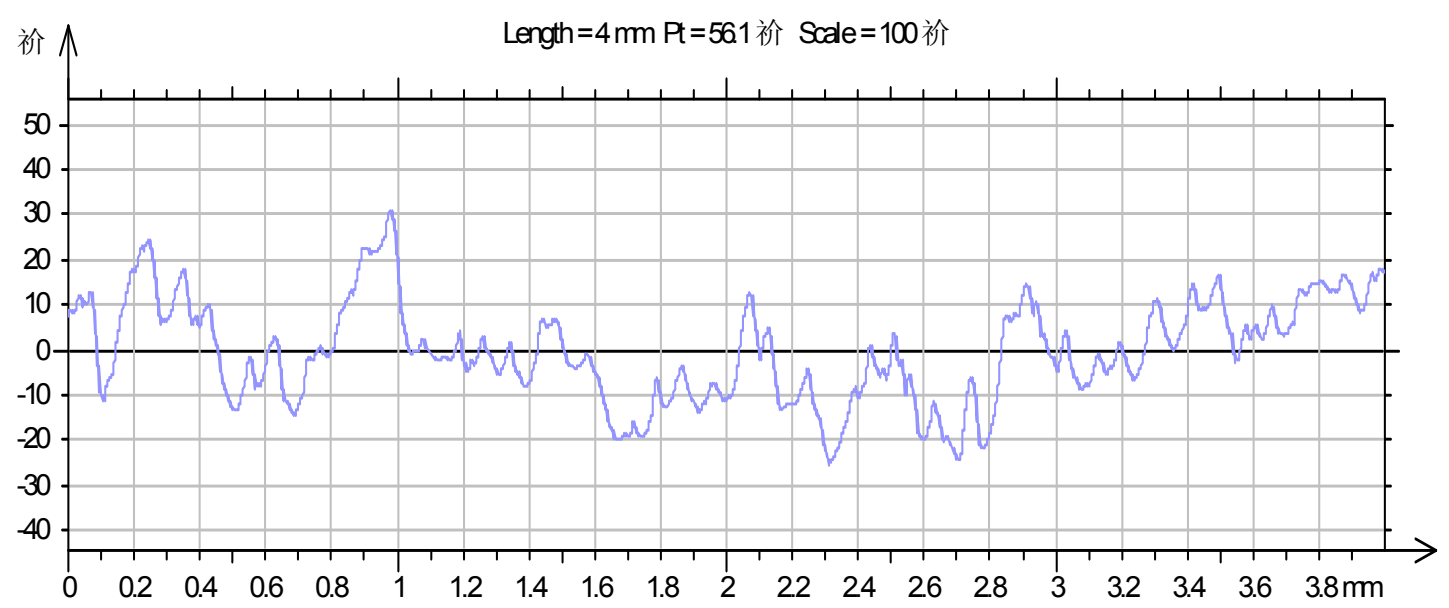

(Sample 4: Run 1) Surface roughness and waviness profile curve at factor setting

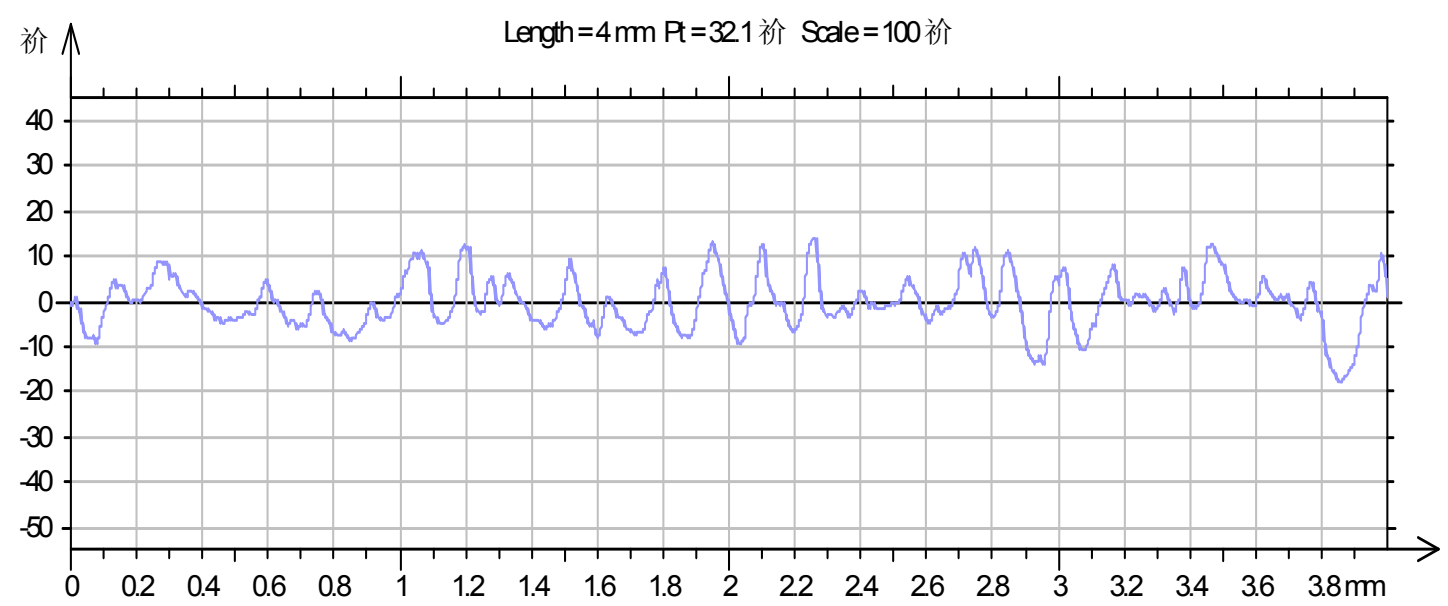

(Sample 5: Run 1) Surface roughness and waviness profile curve at factor setting

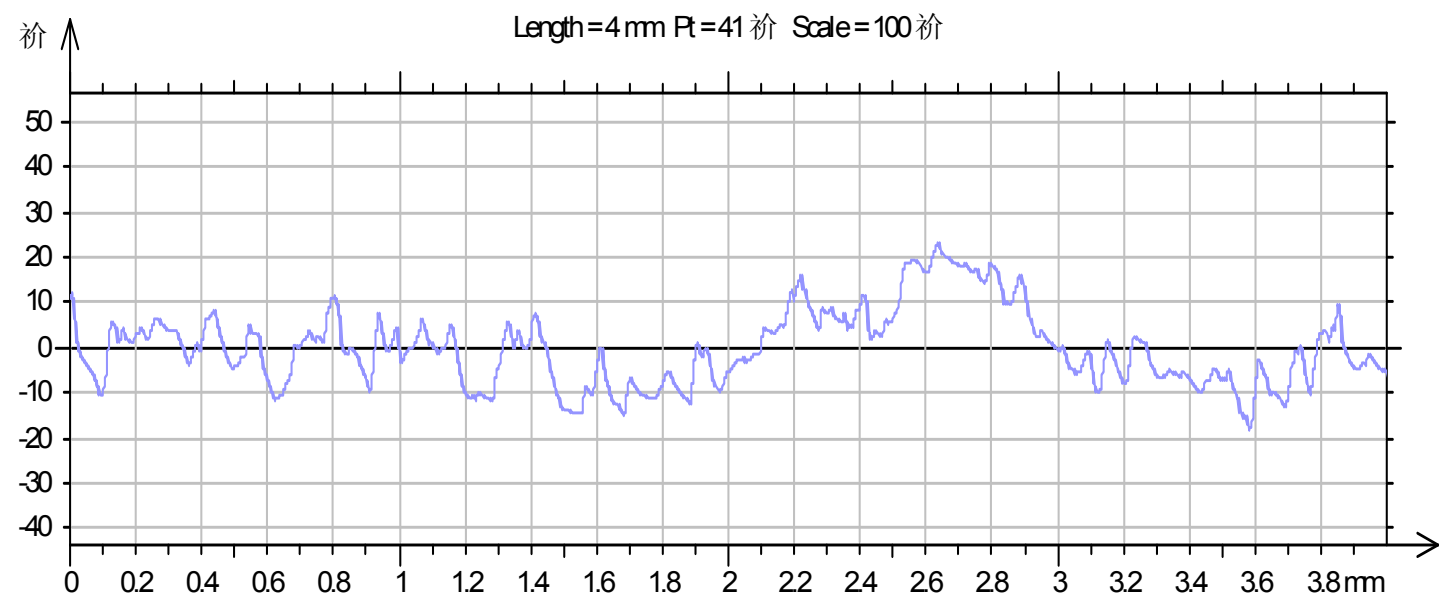

(Sample 6: Run 1) Surface roughness and waviness profile curve at factor setting 


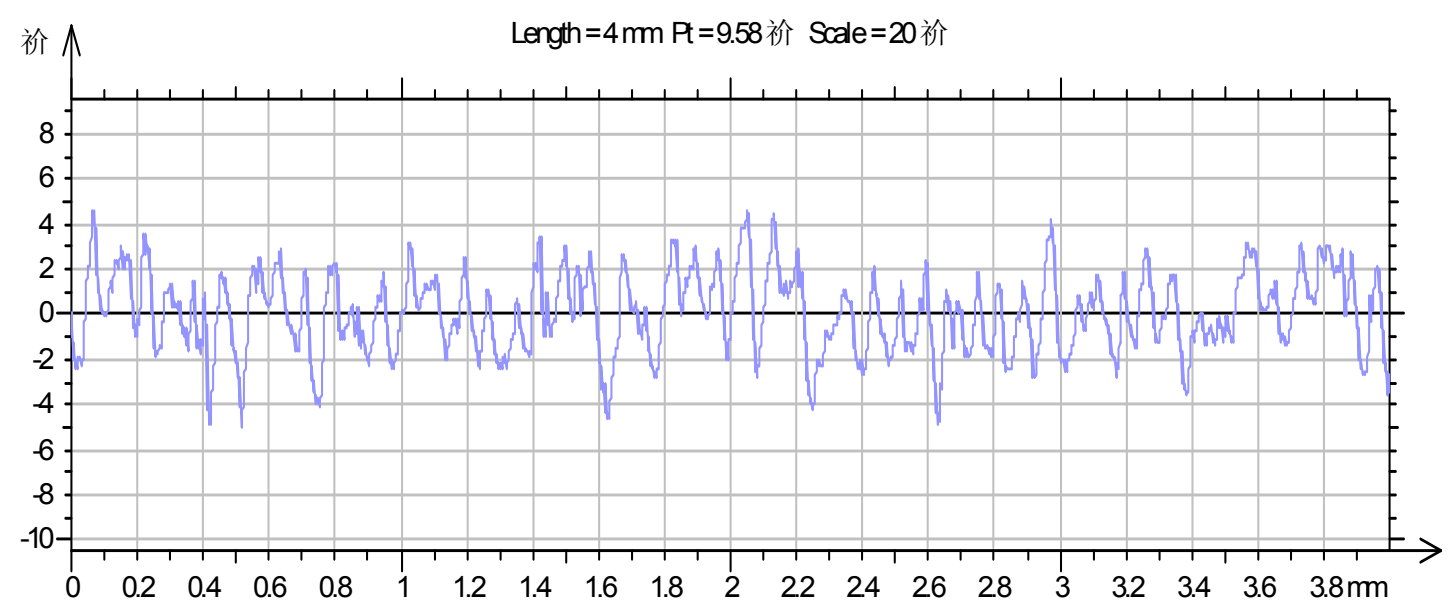

(Sample 7: Run 1) Surface roughness and waviness profile curve at factor setting

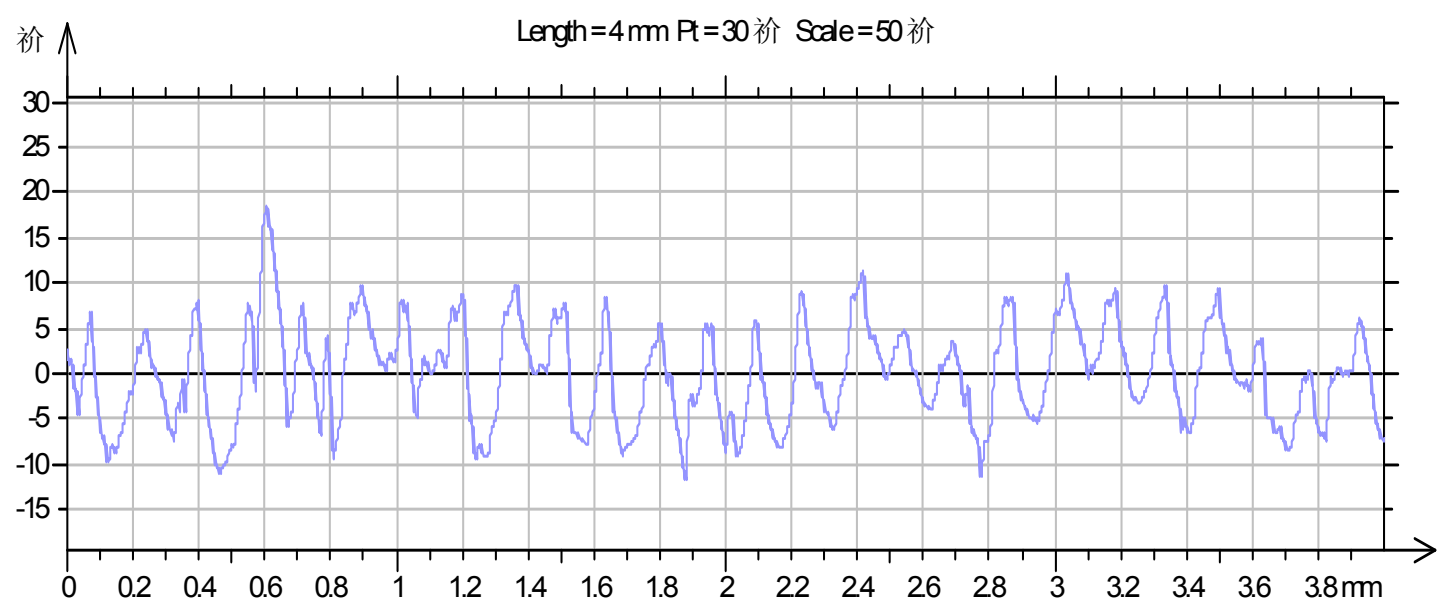

(Sample 8: Run 1) Surface roughness and waviness profile curve at factor setting

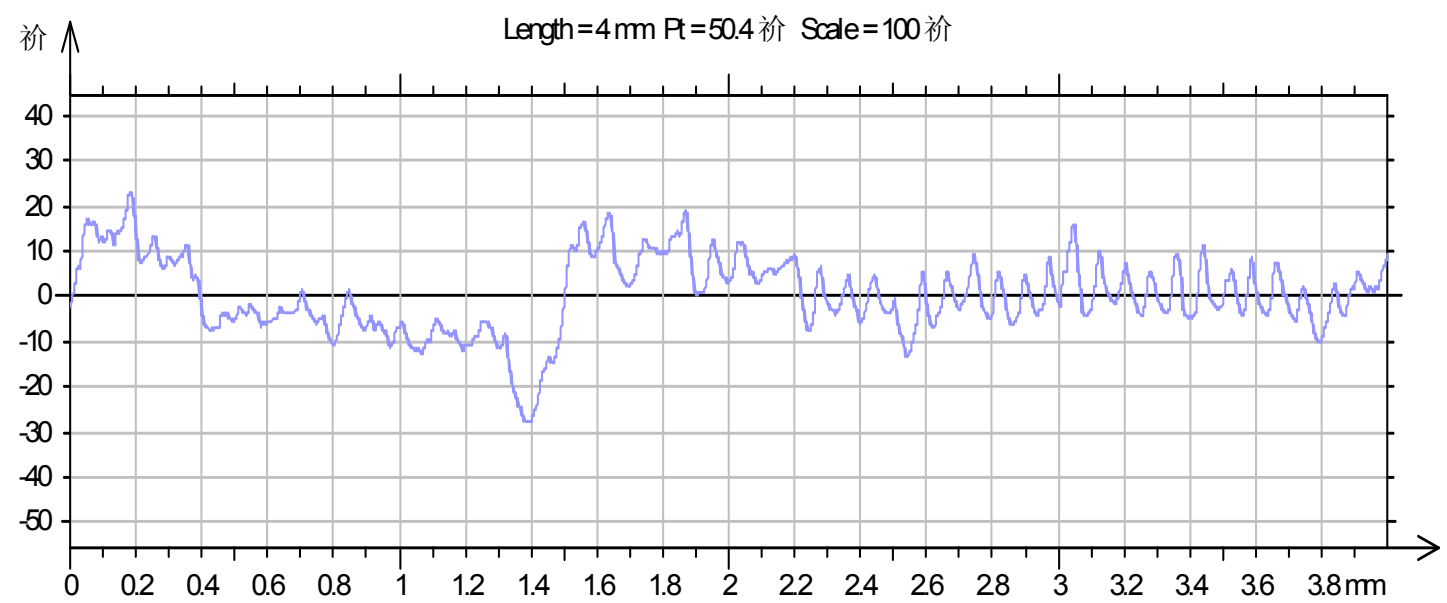

(Sample 9: Run 1) Surface roughness and waviness profile curve at factor setting 